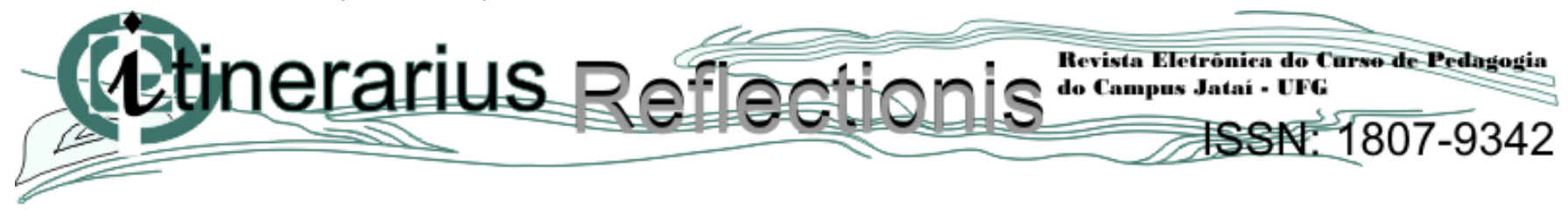

\title{
CONCEPÇÕES DE DISCENTES DO ENSINO FUNDAMENTAL DE FORMOSA (GO) SOBRE O ENSINO DA DISCIPLINA DE CIÊNCIAS
}

\author{
Rafael Gonçalves Bezerra \\ Instituto Federal de Educação, Ciência e Tecnologia de Goiás - \\ Câmpus Formosa \\ E-mail: ra.fagonalves@hotmail.com
}

Lucy Mirian Campos Tavares Nascimento

Mestre em Ensino de Ciências

Professora do Instituto Federal de Educação, Ciência e Tecnologia de Goiás -

Câmpus Formosa

E-mail: lucycmb@gmail.com

\begin{abstract}
RESUMO: O objetivo deste estudo foi o de investigar as percepções sobre o ensino da disciplina de Ciências Naturais de setenta e cinco discentes matriculados em quatro estabelecimentos de ensino de Formosa-GO, dois municipais e dois estaduais. Os pontos investigados foram o nível de dificuldade atribuído a essa disciplina e estratégias didáticas utilizadas pelo professor para a aprendizagem dos alunos. 0 desenvolvimento do trabalho pautou-se nos princípios da metodologia de pesquisa quali-quantitativa. Para sondar as ideias dos discentes aplicou-se um questionário com perguntas abertas. Os dados obtidos por meio das perguntas foram analisados a partir das técnicas da estatística descritiva e da análise de conteúdo. No que tange à visão acerca da disciplina de Ciências, a maioria dos pesquisados disciplina de Ciências tem um grau de dificuldade mediano, relataram que os fatores que mais influenciam para o interesse são os conteúdos e a maneira pela qual são apresentados aos discentes, como uso de vídeos e experiência, e, por fim, afirmaram que a quantidade excessiva de textos e atividades sem maiores esclarecimentos e participação são fatores que contribuem para o desinteresse nas aulas de Ciências.
\end{abstract}

Palavras-chave: Educação. Ensino de Ciências. Estratégias didáticas. Alunos.

ABSTRACT: This article investigates the perceptions about teaching the discipline of Natural Sciences of seventy-five students enrolled in four schools in Formosa-GO, two municipal and two state. The points investigated were difficulty level assigned to that discipline and strategies used by the teacher to student learning. The development work was based on the principles of the methodology of qualitative and quantitative research. To probe the ideas of the students was applied a questionnaire with open questions. The data obtained through the questions were analyzed from the techniques of descriptive statistics and content analysis. Regarding the vision of the discipline of Sciences, the majority of respondents indicated that the discipline has a median degree of difficulty, reported that the factors that most influence for interest are the content and the way they are presented to the students, such as use videos and 


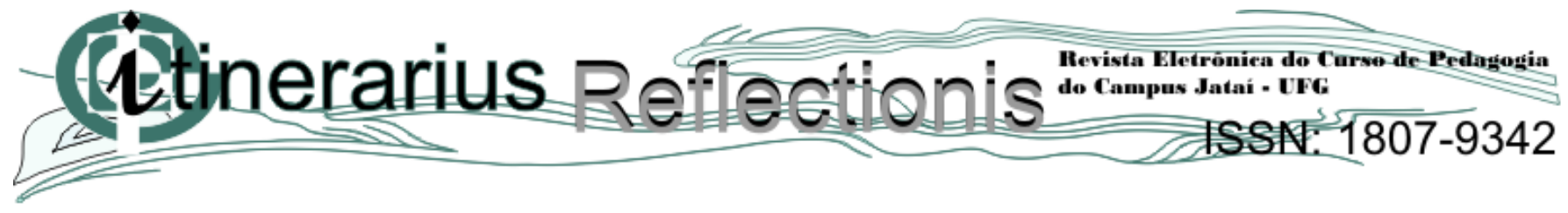

experience, and, finally, said that excessive amount of texts and activities without explanation and participation are factors that contribute to the lack of interest in Natural Sciences class.

Keywords: Education. Science education. Didactic strategies. Students.

\section{Introdução}

Ao longo da história do ensino de Ciências no Brasil, muitas são as preocupações com o processo de ensino e aprendizagem de conhecimentos científicos. De acordo com os Parâmetros Curriculares Nacionais (BRASIL, 1998), o ensino de Ciências Naturais é relativamente recente na educação escolar fundamental, detendo hoje propostas de ensino que reconhecem a relação dos diversos valores humanos com a Tecnologia e com as demais questões sociais e ambientais. Portanto, é essencial considerar o "desenvolvimento cognitivo dos estudantes, relacionado a suas experiências, sua idade, sua identidade cultural e social, e os diferentes significados e valores que as Ciências Naturais podem ter para eles, para que a aprendizagem seja significativa" (idem, p. 27).

Consoante Krasilchik (2008), no estágio atual do ensino brasileiro, a disciplina de Ciências pode ser uma das mais relevantes e merecedoras da atenção dos alunos, ou uma das mais insignificantes e pouco atraentes. Para a autora, a visão que os discentes têm acerca da disciplina depende do que será ensinado e de como isso será feito.

No entanto, muitas práticas, no âmbito do ensino escolar das ciências, tomam por base a mera transmissão de informações, tendo como recurso exclusivo o livro didático e a sua descrição na lousa. Todavia, as atividades de ensino dessa disciplina (e das demais) deve ir além da passividade do aluno e a reprodução mecânica de nomes difíceis por parte do professor, uma vez que a educação escolar têm papel essencial no desenvolvimento de cidadãos, na medida em dominam passam a dominar os conhecimentos produzidos durante a história da humanidade e, ao mesmo tempo, os reelaboram.

Nesse contexto, emerge o papel do professor, uma vez que compete ao mesmo conduzir ações visando à compreensão de saberes científicos por parte de seus educandos. Dominar teorias científicas e suas vinculações com as tecnologias é uma das competências que um educador deve ter; e para isso é necessário que a formação de docentes seja pautada na construção de um conhecimento sólido ao tratar os diferentes desdobramentos da profissão, como, por exemplo, lidar com novas tecnologias, inclusão de alunos e educação de jovens e adultos. Sendo assim, o desenvolvimento do estágio é necessário à formação profissional, a fim de adequar essa formação às expectativas do mercado de trabalho, mas acima 


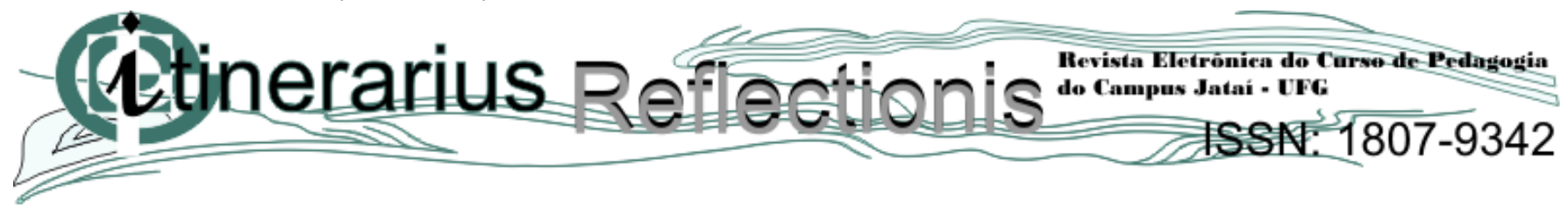

de tudo, atender expectativas sociais, da localidade onde o licenciado irá atuar. Nesse sentido, argumentam Lima e Vasconcelos (2006, p. 406):

Um desafio imposto ao professor é aplicar práticas pedagógicas acompanhadas de práticas conceituais; ou seja, relacionar os conceitos à realidade do aluno, dando significado e importância ao assunto apresentado. Tal desafio requer a integração de disciplinas, conhecimentos específicos e qualificações humanas, como habilidades, competências, atitudes e valores.

Partindo desse posicionamento, mas buscando analisar os outros sujeitos do processo de ensino e aprendizagem - os alunos - este trabalho decorre das atividades desenvolvidas no âmbito do Estágio Supervisionado do curso de Licenciatura em Ciências Biológicas, do Instituto Federal de Educação, Ciência e Tecnologia de Goiás, Câmpus Formosa. A pesquisa ora relatada foi realizada junto aos discentes matriculados em estabelecimentos de ensino do município de Formosa, que carece de estudos atinentes ao ensino e aprendizagem das ciências. Sendo assim, objetivou-se investigar quais as percepções dos sujeitos pesquisados a respeito do ensino da disciplina de Ciências Naturais, a partir do nível de dificuldade atribuído a essa disciplina e estratégias didáticas utilizadas pelo professor para a aprendizagem dos alunos.

\section{Metodologia}

O desenvolvimento o trabalho de pesquisa, de caráter exploratório, seguiu os princípios da metodologia de pesquisa qualitativa, que constitui "[...] uma metodologia de investigação que enfatiza a descrição, a indução, a teoria fundamentada e o estudo das percepções pessoais" (BOGDAN \& BIKLEN 1994, p. 11). Além disso, o estudo imbuiu-se de um caráter quantitativo na medida em que recorreu às técnicas da estatística descritiva para mensurar e comparar os resultados obtidos para posterior generalização (CRUZ, 2009).

O grupo de pesquisa constituiu-se de setenta e cinco estudantes, matriculados no 9o ano (8a série), de quatro estabelecimentos de ensino fundamental do município de Formosa (GO), dois estaduais e dois municipais. Tais estabelecimentos são representados pelas letras A, B, C e D.

A coleta de dados foi realizada por meio de questionários com três perguntas abertas, indagando a respeito das percepções dos discentes acerca das aulas Ciências:

- Qual o nível de dificuldade que você atribui às aulas de Ciências? Por quê?

- O que você mais gosta das aulas de ciências?

- O que você menos gosta das aulas de ciências? 


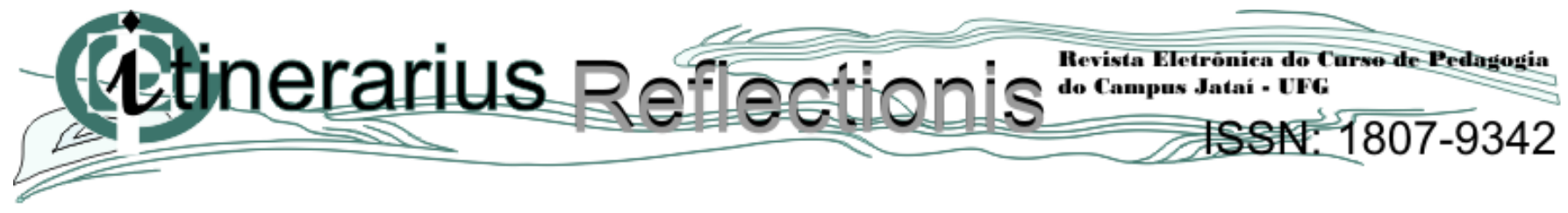

No que tange ao tratamento dos dados provindos das respostas dos estudantes, as perguntas fechadas foram analisadas a partir das técnicas da estatística descritiva (frequências relativa e absoluta). As questões abertas foram analisadas a partir da técnica qualitativa de análise de conteúdo (BARDIN, 2002).

Por fim, para apresentação dos resultados, às repostas tiveram tratamento estatístico com o fito de verificar as categorias com maior incidência de respostas, além da construção de tabelas, quadros e gráficos.

\section{Resultados e Discussão}

A primeira questão procurou saber a opinião acerca de possíveis dificuldades com a disciplina: "Qual o nível de dificuldade que você atribui às aulas de Ciências? Por quê?". Segundo a maioria dos discentes dos quatro estabelecimentos, a disciplina de Ciências ora é vista como difícil, ora é vista como fácil, daí a preponderância da categoria "mais ou menos" (Gráfico 1).

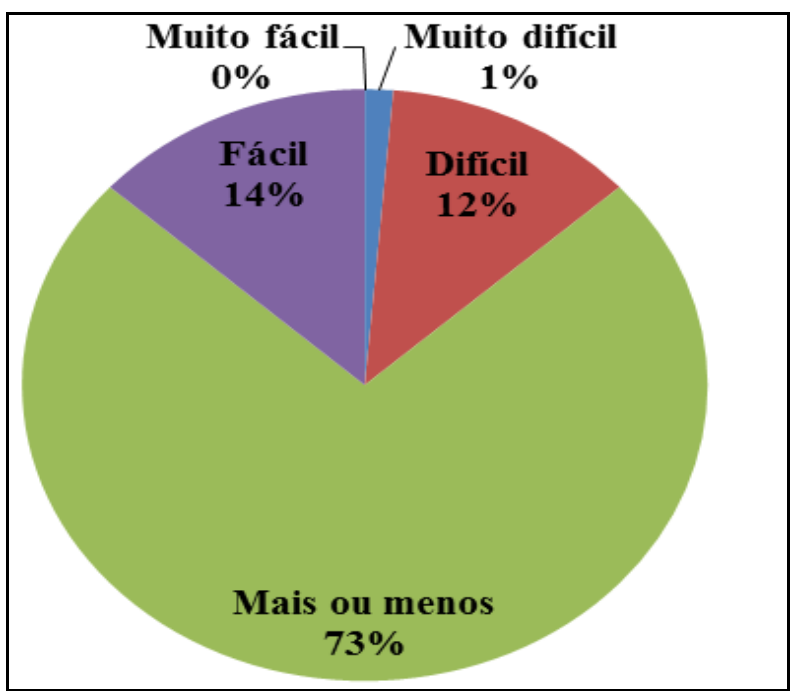

Gráfico 1: Categorias concernentes à dificuldade com a disciplina de Ciências em relação às respostas de todos os estudantes. Fonte: dados da pesquisa.

Conforme evidencia o Gráfico 1, em todas as escolas a categoria de maior preponderância foi a de que os alunos consideram a disciplina de Ciências às vezes fácil, às vezes difícil. Na unidade escolar C foi constatado o maior índice de respostas atribuídas à categoria "mais ou menos".

De acordo com o Quadro 1, apenas um discente da escola D, 1\% da amostra total, assinalou que a disciplina de Ciências era muito difícil. Para 12\% dos alunos pesquisados a disciplina de Ciências é difícil. Essa percepção pode estar associada ao fato de a disciplina deter rigor epistemológico das ciências, isto é, a 


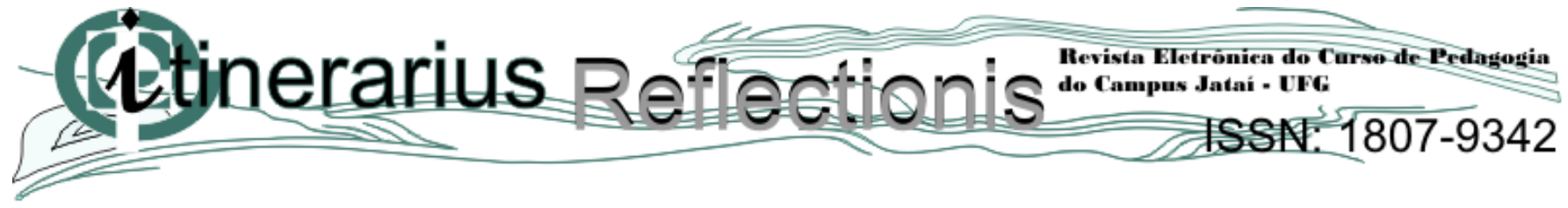

existência de um vocabulário considerado difícil, mas muitas vezes enfatizado sem significância, resultando na mera memorização, e também da necessidade de compreender fenômenos naturais por meio de equações e fórmulas. Justificativas semelhantes às encontradas na categoria "difícil" foram dadas pelos discentes (73\%) que assinalaram que disciplina em questão é vista como "mais ou menos". Porém, de acordo com os resultados observados, é necessário desenvolver leituras e interpretações, sem abrir mão de experimentos para um maior entendimento do fenômeno estudado.

Já a categoria "muito fácil" não foi assinalada por nenhum pesquisado. A partir da análise às justificativas atribuídas a essas respostas, constatou-se que alguns alunos atribuem facilidade (13\%) a disciplina de Ciências. Tal referência pode estar atrelada ao próprio interesse demonstrado pelos alunos. A explicação do professor também foi destacada como um meio facilitador para compreender a disciplina; portanto o professor que bem explica, domina bem o conteúdo, pode fazer com que os alunos se interessem mais (Quadro 1).

Quadro 1: Opiniões dos alunos das quatro unidades de ensino acerca de dificuldades ou não com a disciplina de Ciências. (Obs.: as respostas foram transcritas conforme foram elaboradas pelos alunos; em parênteses identifica-se a escola a qual pertence o discente).

\begin{tabular}{|c|c|c|c|c|c|c|}
\hline \multirow{2}{*}{ Categoria } & \multirow{2}{*}{ Exemplos de respostas } & \multicolumn{4}{|c|}{ Unidade escolar } & \multirow{2}{*}{ Total } \\
\hline & & $A(n=13)$ & $B(n=20)$ & $C(n=21)$ & $D(n=21)$ & \\
\hline Muito difícil & "É muito dificiu." (D) & $0 \%$ & $0 \%$ & $0 \%$ & $5 \%$ & $1 \%$ \\
\hline Difícil & $\begin{array}{l}\text { "Eu ainda não peguei o jeito". (A) } \\
\text { "Por causa de alguns nomes não muito fácil de } \\
\text { decorar."(B) } \\
\text { "Porque tem palavras difíceis, que não conseguimos } \\
\text { pegar." (C) } \\
\text { "Por causa das equações." (D) }\end{array}$ & $15 \%$ & $5 \%$ & $10 \%$ & $19 \%$ & $12 \%$ \\
\hline $\begin{array}{l}\text { Mais } \\
\text { ou } \\
\text { menos }\end{array}$ & $\begin{array}{l}\text { "Por que tem umas coisas que não aprendi ainda mais } \\
\text { vou aprender". (A) } \\
\text { "Porque quando você pensa que e fácil la vem } \\
\text { perguntas diferentes em contexto por isso é mais ou } \\
\text { menos." (B) } \\
\text { "Por que tem algumas palavras difícil di ler." (B) } \\
\text { "Porque é uma materia que se requer mais atenção e } \\
\text { mais leitura" (C) } \\
\text { "Porque as vezes tem umas contas de matemática e } \\
\text { eu não sou muito boa. Então é mais ou menos." (D) } \\
\text { "Porque não curto muito ciências." (D) }\end{array}$ & $62 \%$ & $70 \%$ & $81 \%$ & $76 \%$ & $74 \%$ \\
\hline Fácil & $\begin{array}{l}\text { "Por que o professor que temos explica muito bem, } \\
\text { então fica fácil entender a matéria." (A) } \\
\text { "A matéria de ciências é uma matéria muito legal, bons } \\
\text { conteúdos, é muito interessante." (A) } \\
\text { "Porque quando realmente se que aprendir as coisas }\end{array}$ & $23 \%$ & $25 \%$ & $10 \%$ & $0 \%$ & $13 \%$ \\
\hline
\end{tabular}




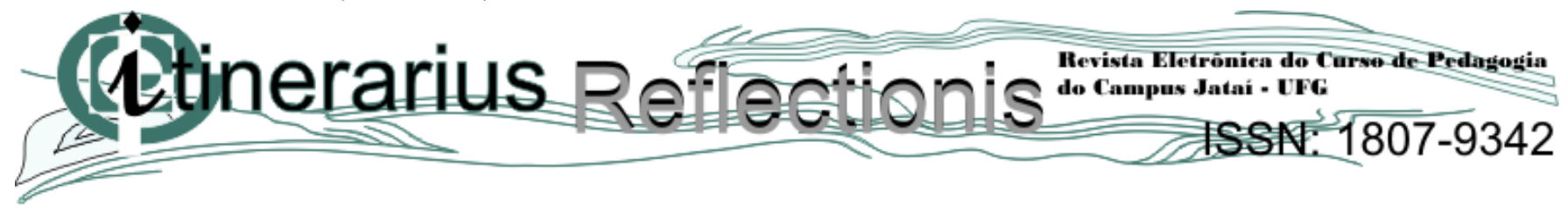

\begin{tabular}{|c|c|c|c|c|c|c|}
\hline & $\begin{array}{l}\text { se tornam fácil." (C) } \\
\text { "Por causa dos livros lendo e estudando fica fácil." (C) }\end{array}$ & & & \\
\hline Muito fácil & - & $0 \%$ & $0 \%$ & $0 \%$ & $0 \%$ & $0 \%$ \\
\hline & Total & $100 \%$ & $100 \%$ & $100 \%$ & $100 \%$ & $100 \%$ \\
\hline
\end{tabular}

Fonte: dados da pesquisa.

De acordo com a Academia Brasileira de Ciências (2008), o ensino de Ciências pode estimular na formação de cidadãos mais conscientes para bem intervir na sociedade contemporânea. Em consequência tem-se o fortalecimento da democracia na medida em que os cidadãos podem opinar conscientemente em temas que afetam o cotidiano. Deste modo, mister se faz a investigar se os estudantes acham interessante, gosta de estudar os conteúdos da disciplina de Ciências Naturais.

Assim, na segunda pergunta do questionário - "O que você mais gosta das aulas de ciências?" verificou-se nas respostas dez categorias emergentes que estão relacionadas à metodologia (ou a recursos didáticos), utilizada na condução das aulas de Ciências.

Na escola A percebeu-se que a exibição de vídeos constitui um recurso significativo para evolver os alunos na disciplina. Por outro lado, os conteúdos têm maior relevância, segundo os alunos, nos estabelecimentos escolares $\mathrm{B}$ e $\mathrm{C}$, que se assemelham quanto à frequência indicada pelos alunos, relativas ao uso do vídeo nas aulas de Ciências.

Quanto à realização de atividades experimentais não se percebe diferença significativa ao se comparar os quatro estabelecimentos de ensino. Houve ainda o apontamento de que o diálogo com o professor é um meio de promover maior interesse pela disciplina e também interação de todos os sujeitos envolvidos no processo de ensino e aprendizagem. Todavia, nos colégios C e D verificou-se a presença de repostas que indicaram que os discentes não mostram estar instigados a se interessar pela disciplina de Ciências, fato evidenciado nas categorias "nada" e "quando acaba" as aulas (Tabela 1).

Tabela 1: Fatores que influenciam no desinteresse dos alunos para com a disciplina de Ciências em cada unidade escolar pesquisada.

\begin{tabular}{|c|c|c|c|c|c|}
\hline \multirow{2}{*}{ Categoria } & \multicolumn{4}{|c|}{ Unidade escolar } & \multirow{2}{*}{ Total } \\
\hline & $A(n=13)$ & $B(n=20)$ & $C(n=21)$ & $D(n=21)$ & \\
\hline Vídeo & $46 \%$ & $10 \%$ & $12 \%$ & $7 \%$ & $17 \%$ \\
\hline Experiências & $23 \%$ & $20 \%$ & $12 \%$ & $20 \%$ & $18 \%$ \\
\hline Conteúdo & $23 \%$ & $35 \%$ & $47 \%$ & $20 \%$ & $32 \%$ \\
\hline Explicação & $8 \%$ & $25 \%$ & $6 \%$ & $7 \%$ & $12 \%$ \\
\hline Diálogo com o(a) professor(a) & $0 \%$ & $5 \%$ & $6 \%$ & $7 \%$ & $5 \%$ \\
\hline Interação & $0 \%$ & $5 \%$ & $6 \%$ & $7 \%$ & $5 \%$ \\
\hline
\end{tabular}




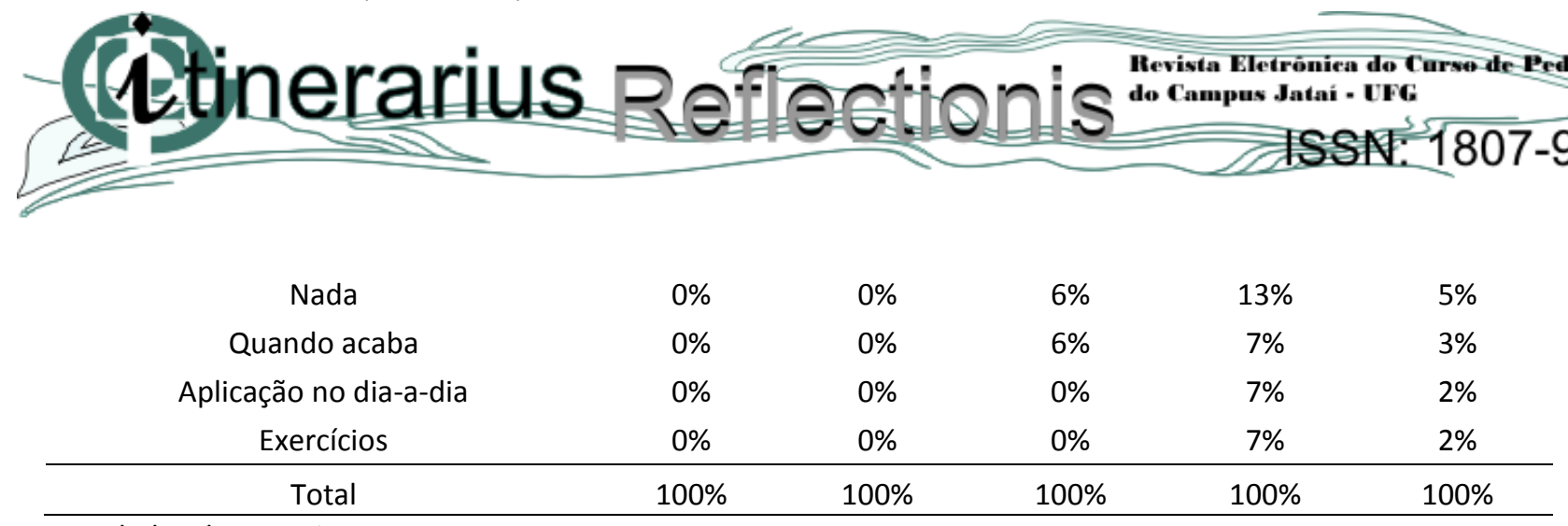

Fonte: dados da pesquisa.

O Gráfico 2 apresenta os resultados por categoria em relação à amostra total de discentes pesquisados.

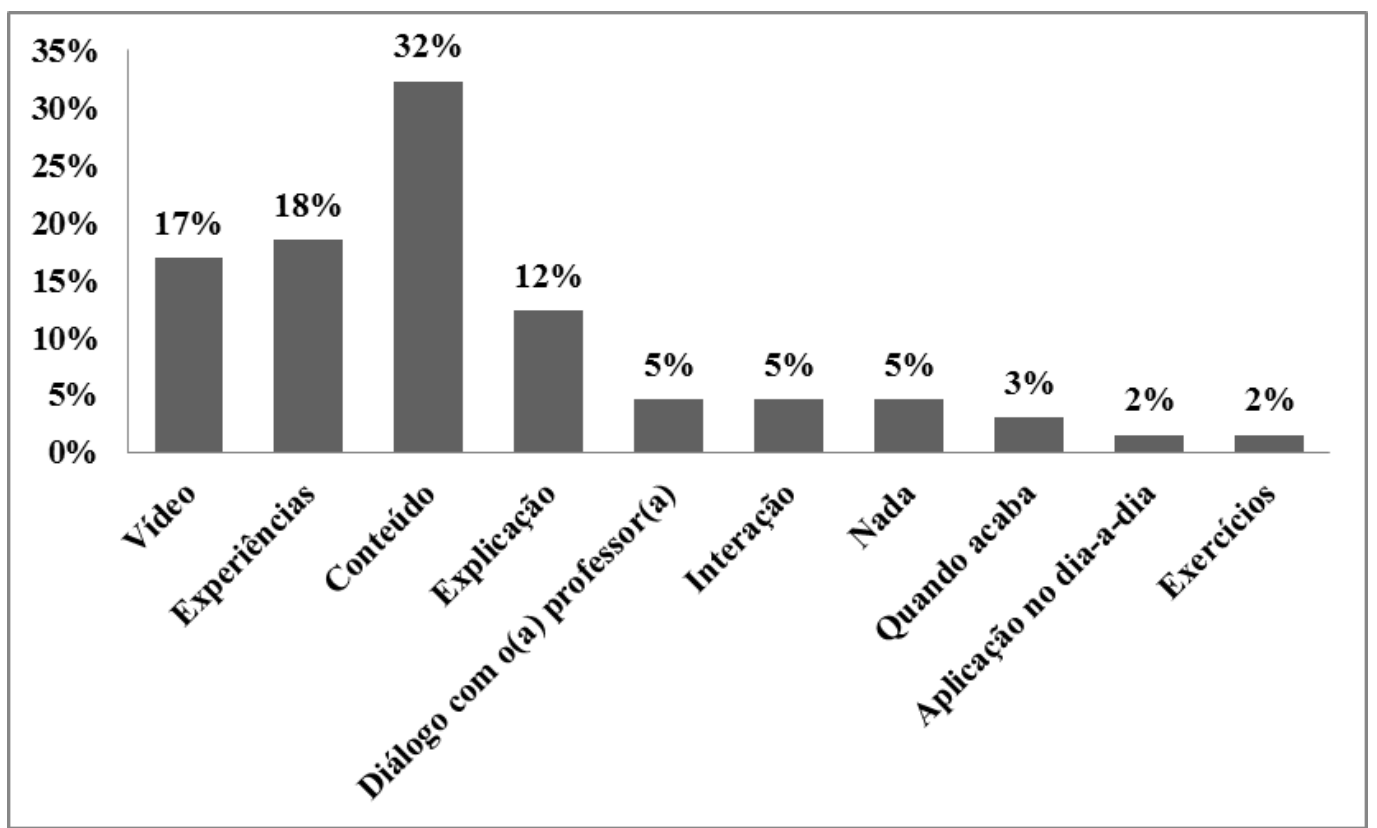

Gráfico 2: Fatores que influenciam na afinidade dos alunos para com a disciplina de Ciências em relação à amostra total de pesquisados. Fonte: dados da pesquisa.

Percebeu-se que os conteúdos que compõem as ciências naturais são os fatores preponderantes que instigam os discentes a despertar interesse pela disciplina. Isso pode significar dizer que, às vezes, certo conteúdo vai se mostrar mais atrativo do que outro; e tal fato evidencia que a metodologia utilizada pelo professor é fator determinante para envolver os alunos e fazer com que se interessem pela disciplina, conforme indagou-se na pergunta anterior.

Experiências e vídeos são recursos metodológicos de relevância considerável para interessar os discentes, possivelmente pelo fato de ambos os recursos poderem ser utilizados para demonstrar determinados fenômenos levando com que os alunos compreendam melhor o que se estuda. Segundo Borges (2002), os professores, tanto no ensino médio e fundamental, consideram que a melhoria na 


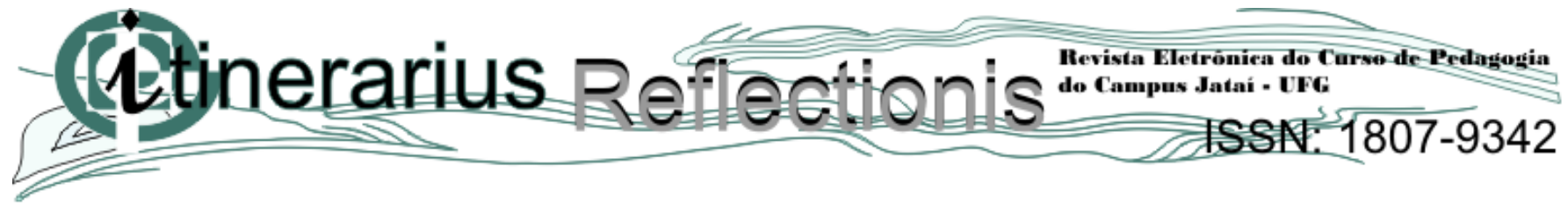

qualidade do ensino passa com a introdução de aulas práticas no cotidiano escolar. Para tal, a explicação do professor também é um recurso fundamental e isso foi apontado pelos discentes, conforme se evidencia nos discursos seguintes:

O que eu mais gosto da aula de ciencias e quando a professora faz a esplicação do que passou no quadro, e quando ajuda os alunos em alguma coisa que não sabemos resolver ou interpretar ${ }^{1}$. (C)

O professor explicando de uma forma muito legal. (B)

Alguns estudantes relataram que não possuem interesse pela disciplina, dizendo que o melhor é quando a aula acaba ou que nada os levam a se interessar. A aplicação dos conteúdos no cotidiano foi apontada, porém de maneira pouco expressiva (2\%), o que evidencia a ausência de significância na aprendizagem, por parte dos alunos, dos conteúdos inerentes às ciências (Quadro 2).

Quadro 2: Categorias emergentes e exemplos de respostas dos discentes à pergunta "O que você mais gosta das aulas de ciências?". (Obs.: em parênteses segue o código da escola na qual o aluno pertence.)

\begin{tabular}{|c|c|c|c|c|c|c|}
\hline \multirow{2}{*}{ Categoria } & \multirow{2}{*}{ Exemplos de respostas } & \multicolumn{4}{|c|}{ Unidade escolar } & \multirow[b]{2}{*}{ Total } \\
\hline & & $A(n=13)$ & $B(n=20)$ & $C(n=21)$ & $D(n=21)$ & \\
\hline Vídeo & $\begin{array}{c}\text { “Os vídeos que o professor passa para } \\
\text { facilitar a explicação." (A) } \\
\text { “Os vídeos que o professor passa } \\
\text { quando vai explicar a matéria." (C) }\end{array}$ & $46 \%$ & $10 \%$ & $12 \%$ & $7 \%$ & $17 \%$ \\
\hline Experiências & $\begin{array}{l}\text { "As experiências cientificas." (A) } \\
\text { "Aulas com experiências" (B) }\end{array}$ & $23 \%$ & $20 \%$ & $12 \%$ & $20 \%$ & $18 \%$ \\
\hline Conteúdo & $\begin{array}{c}\text { "As matérias são muito interessantes, } \\
\text { a gente aprende muito." (A) } \\
\text { "Aula sobre o corpo humano" (B) }\end{array}$ & $23 \%$ & $35 \%$ & $47 \%$ & $20 \%$ & $32 \%$ \\
\hline Explicação & $\begin{array}{c}\text { “Quando o professor ler para nos e } \\
\text { explica” (B) } \\
\text { “O que eu mais gosto da aula de } \\
\text { ciencias e quando a professora faz a } \\
\text { esplicação do que passou no quadro, } \\
\text { e quando ajuda os alunos em alguma } \\
\text { coisa que não sabemos resolver ou } \\
\text { interpretar." (C) }\end{array}$ & $8 \%$ & $25 \%$ & $6 \%$ & $7 \%$ & $12 \%$ \\
\hline $\begin{array}{l}\text { Diálogo com } \\
\text { o(a) } \\
\text { professor(a) }\end{array}$ & $\begin{array}{l}\text { "Meu dialogo com o professor faz } \\
\text { com que ganhe mais" (B) }\end{array}$ & $0 \%$ & $5 \%$ & $6 \%$ & $7 \%$ & $5 \%$ \\
\hline Interação & $\begin{array}{c}\text { "Pode interagir com o professor e os } \\
\text { colegas sobre os assuntos" (B) }\end{array}$ & $0 \%$ & $5 \%$ & $6 \%$ & $7 \%$ & $5 \%$ \\
\hline Nada & "Nada" (D) & $0 \%$ & $0 \%$ & $6 \%$ & $13 \%$ & $5 \%$ \\
\hline Quando & "Quando acaba" (C) & $0 \%$ & $0 \%$ & $6 \%$ & $7 \%$ & $3 \%$ \\
\hline
\end{tabular}

\footnotetext{
${ }^{1}$ Ressaltamos que os discursos serão reproduzidos da maneira pela qual foram elaborados pelos discentes.
} 
Primeiro semestre 2014, volume 1, número 16.

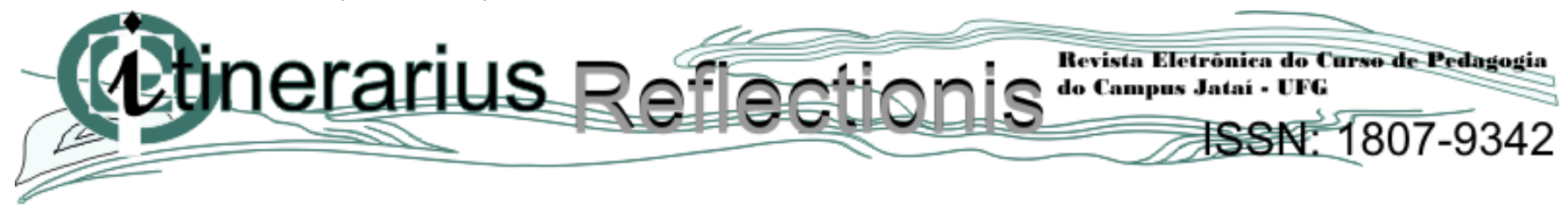

\begin{tabular}{|c|c|c|c|c|c|c|}
\hline acaba & & & & & \\
\hline $\begin{array}{c}\text { Aplicação no } \\
\text { dia-a-dia }\end{array}$ & $\begin{array}{c}\text { "o motivo é que no qual mais gosto } \\
\text { em ciências é sua relação com nosso } \\
\text { dia a dia." (D) }\end{array}$ & $0 \%$ & $0 \%$ & $0 \%$ & $7 \%$ & $2 \%$ \\
\hline Exercícios & $\begin{array}{c}\text { "Alguns exercicios algumas atividades } \\
\text { faceis algumas aprendo nas aulas" (D) }\end{array}$ & $0 \%$ & $0 \%$ & $0 \%$ & $7 \%$ & $2 \%$ \\
\hline \multicolumn{2}{|c|}{ Total } & $100 \%$ & $100 \%$ & $100 \%$ & $100 \%$ & $100 \%$ \\
\hline
\end{tabular}

Fonte: dados da pesquisa.

Em contrapartida, a pergunta de número 3 indagou: "O que você menos gosta das aulas de ciências?". Os resultados estão evidenciados no Gráfico 3.

Nas unidades escolares A e D, a necessidade de aprender conteúdos que trabalham com cálculos, como Leis de Newton e cálculos estequiométricos químicos, constitui um motivo de desinteresse na disciplina, conforme é apontado no discurso a seguir:

Vários cálculos, numeros e outras coisas difíceis de se aprender. (C)

Além disso, os discentes relataram que quando o professor faz uso de texto e tarefas sem explicação, ou seja, só cópia no quadro negro, isso colabora para que a disciplina seja considerada desinteressante. Isso pode ocorrer quando o professor não domina determinado conteúdo, ou demonstra cansaço devido a uma elevada carga horária de aulas semanal, bem como a falta de tempo para planejar aulas. Nomes complicados, muitos exercícios e falta de clareza na explicação do livro didático também são agentes que levam ao desinteresse na disciplina de Ciências. Nesse sentido Malafaia e Rodrigues (2008) que a aplicação de muitos exercícios cuja exigência é a memorização do conteúdo constitui em um problema no ensino de Ciências. O papel do professor seria o de orientar os educandos em situações de aprendizagem e na resolução dos exercícios, de maneira a clarificar as dificuldades e obstáculos que inerentemente fazem parte do processo de aprendizagem.

O Gráfico 3 apresenta os resultados por categoria em relação à amostra total de discentes pesquisados. 

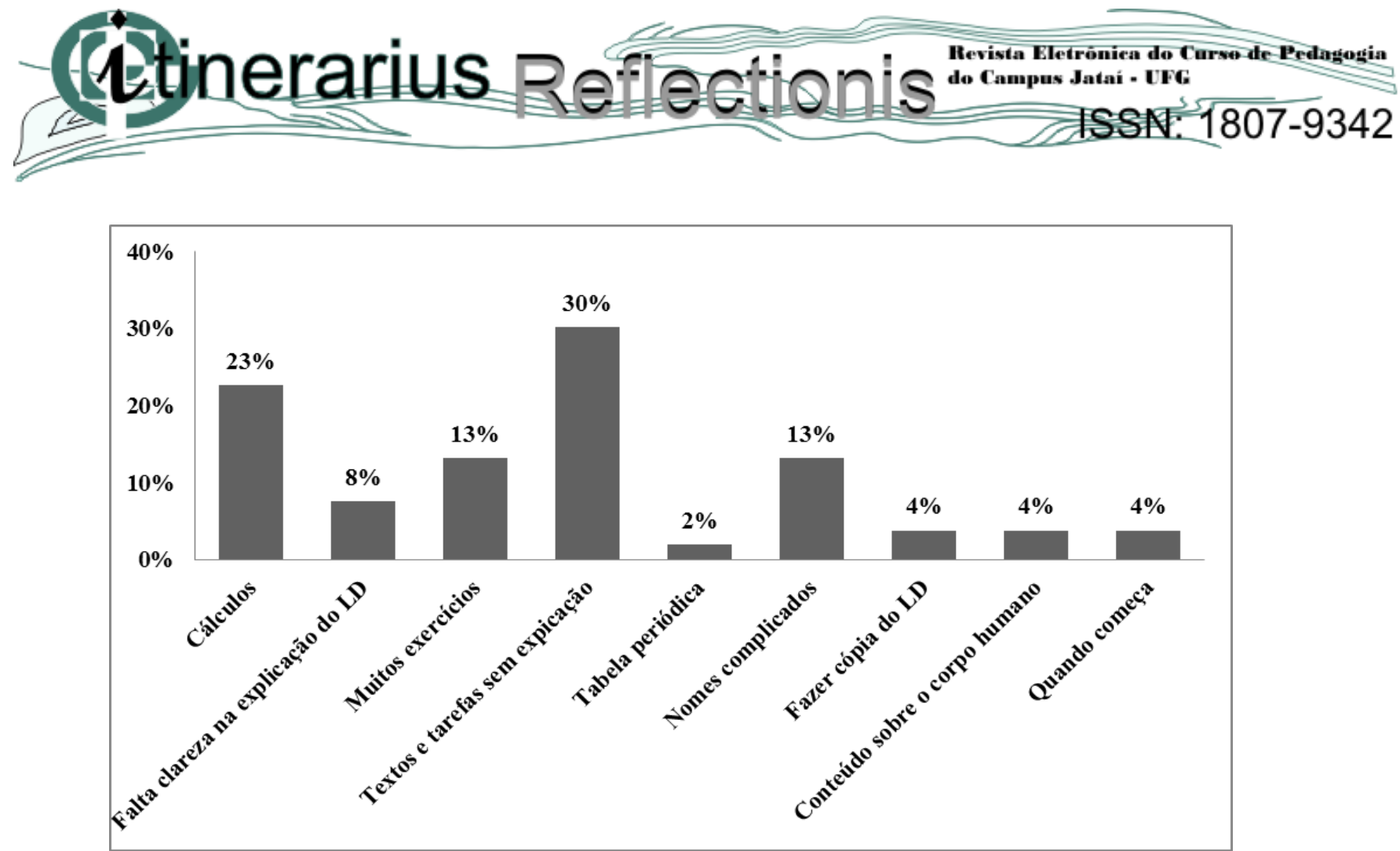

Gráfico 3: Fatores que influenciam no desinteresse dos alunos para com a disciplina de Ciências em relação à amostra total de pesquisados. Fonte: dados da pesquisa.

Os alunos apontam os textos e tarefas sem explicação, com 30\%, como um dos fatores preponderantes que os desmotivam a se desinteressarem pelas ciências (Quadro 3). Outra categoria apontada foi o estudo de cálculos destacado por $23 \%$ dos discentes, o que pode ser explicado pelo fato de se exigir frequentemente abstração para se entender entendimento dos conceitos básicos do conteúdo. Do mesmo modo, é mister destacar que os próprios docentes podem ter dificuldades teórica e metodológicas para abordar conteúdos. Segundo Lima e Vasconcelos (2006), em trabalho sobre a as principais dificuldades e metodologias de ensino de Ciências da rede pública municipal do Recife, verificaram que os conteúdos de Noções de Física e Química são considerados os mais difíceis e, juntos, respondem pela maior frequência de citações. Os próprios docentes apontaram que as dificuldades se devem a carência desses assuntos na formação inicial.

Quadro 3: Categorias emergentes e exemplos de respostas dos discentes à pergunta "o que você menos gosta das aulas de ciências?”. (Obs.: em parênteses segue o código da escola na qual o aluno pertence.)

\begin{tabular}{|c|c|c|c|c|c|c|}
\hline \multirow{2}{*}{ Categoria } & \multirow{2}{*}{ Exemplos de respostas } & \multicolumn{4}{|c|}{ Unidade escolar } & \multirow{2}{*}{ Tota } \\
\hline & & $A(n=13)$ & $B(n=20)$ & $C(n=21)$ & $D(n=21)$ & \\
\hline Cálculos & $\begin{array}{l}\text { "Vários cálculos, numeros e outras } \\
\text { coisas difíceis de se aprender." (C) }\end{array}$ & $50 \%$ & $0 \%$ & $7 \%$ & $33 \%$ & $23 \%$ \\
\hline $\begin{array}{l}\text { Falta clareza na } \\
\text { explicação do LD }\end{array}$ & $\begin{array}{l}\text { "Alguns dos livros didáticos não } \\
\text { explicam direito o conteúdo." (A) }\end{array}$ & $8 \%$ & $8 \%$ & $0 \%$ & $13 \%$ & $8 \%$ \\
\hline Muitos exercícios & "Muitas vezes tem muitos exercícios & $8 \%$ & $17 \%$ & $14 \%$ & $13 \%$ & $13 \%$ \\
\hline
\end{tabular}




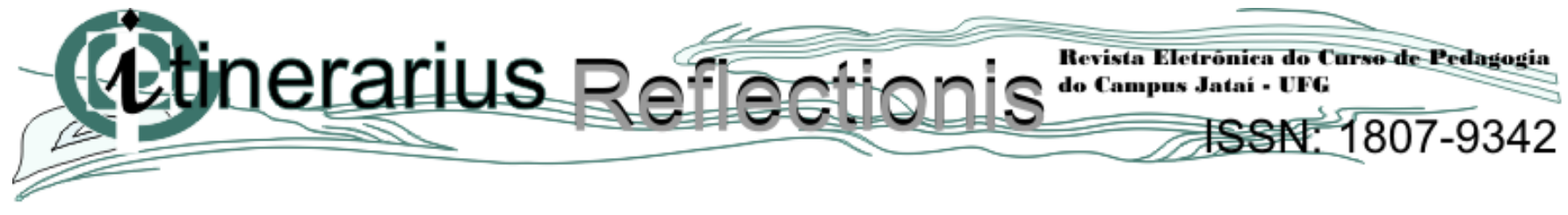

\begin{tabular}{|c|c|c|c|c|c|c|}
\hline & e não damos conta." & & & & & \\
\hline $\begin{array}{l}\text { Textos e tarefas } \\
\text { sem explicação }\end{array}$ & $\begin{array}{l}\text { "Quando ele só passa texto e tarefa, } \\
\text { sem parar para explicar." (A) }\end{array}$ & $8 \%$ & $33 \%$ & $50 \%$ & $27 \%$ & $30 \%$ \\
\hline Tabela periódica & "Da tabela periódica." (A) & $8 \%$ & $0 \%$ & $0 \%$ & $0 \%$ & $2 \%$ \\
\hline $\begin{array}{l}\text { Nomes } \\
\text { complicados }\end{array}$ & $\begin{array}{l}\text { "Ter que diferenciar nomes, saber a } \\
\text { junção de cada elemento etc." (C) }\end{array}$ & $17 \%$ & $17 \%$ & $7 \%$ & $13 \%$ & $13 \%$ \\
\hline Fazer cópia do LD & $\begin{array}{l}\text { "Quando nos temos que copiar do } \\
\text { livro." }\end{array}$ & $0 \%$ & $8 \%$ & $7 \%$ & $0 \%$ & $4 \%$ \\
\hline $\begin{array}{l}\text { Conteúdo sobre o } \\
\text { corpo humano }\end{array}$ & $\begin{array}{l}\text { "Sobre o corpo humano, eu acho } \\
\text { isso um absurdo porque, eu não } \\
\text { gosto das aulas sobre o corpo } \\
\text { humano." (B) }\end{array}$ & $0 \%$ & $17 \%$ & $0 \%$ & $0 \%$ & $4 \%$ \\
\hline Quando começa & "Quando começa." (C) & $0 \%$ & $0 \%$ & $14 \%$ & $0 \%$ & $4 \%$ \\
\hline & Total & $100 \%$ & $100 \%$ & $100 \%$ & $100 \%$ & $100 \%$ \\
\hline
\end{tabular}

Fonte: dados da pesquisa.

Muitos exercícios e nomes complicados, também aparecem como fatores que desmotivam os alunos a se interessarem por Ciências, sendo destacado igualmente por $13 \%$ dos alunos. 0 fato de essas categorias terem tido o mesmo destaque pode estar relacionado ao fato do conhecimento da nomenclatura ser necessário para a resolução de exercícios. Como o livro didático é recurso importante para o ensino/aprendizagem de ciências, houve discentes que apontaram (8\%) a falta de clareza na explicação do manual como colaborador para o desinteresse na disciplina, o que se agrava ainda mais quando se percebe a proposição de atividades que visam apenas efetuar cópias de conteúdos desse recurso didático.

Chama atenção a justificativa de terem surgido discursos que indicassem o estudo de conteúdos sobre o corpo humano (4\%) como atividade que leva ao desgosto pela disciplina, uma vez que é um dos conteúdos que, geralmente, interessa os estudantes versa sobre o estudo do corpo humano. Assim corrobora a pesquisa de Lima e Vasconcelos (2006), os quais constataram que, na visão dos docentes, a reprodução humana é o assunto que mais desperta atenção dos discentes da $7 \underline{a}$ série $\left(8^{\circ}\right.$ ano) do ensino fundamental. Do mesma maneira, Santos et al. (2011) perceberam que os alunos têm maior interesse pelo estudo do corpo humano.

Além disso, houve alunos que relataram que quando a aula começa constitui um fator desmotivante, o que pode indicar o desconhecimento do lado bom da disciplina. Assim, o aluno não tem interesse em aprender. Por outro lado, quando há o interesse, é possível que os discente tenha mais 
Primeiro semestre 2014, volume 1, número 16.

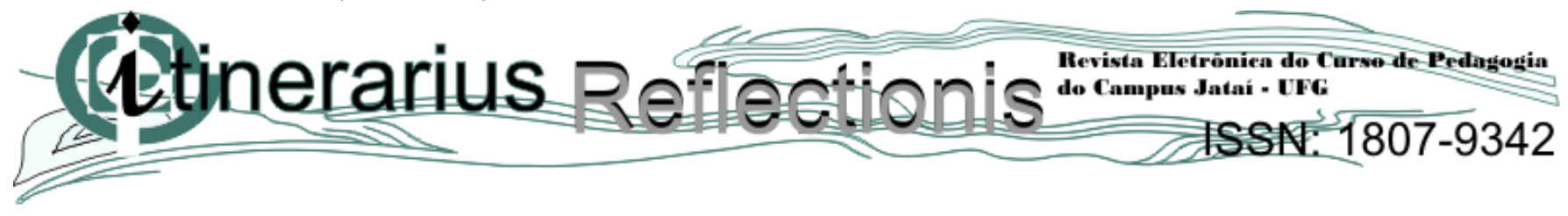

motivação para os estudos, de modo a enfrente as dificuldade que por venturar vem surgir na trajetória da aprendizagem (TAPIA; MONTEIRO, 2003).

\section{Considerações Finais}

Esta pesquisa proporcionou uma contribuição inicial a respeito do ensino da disciplina de Ciências no município de Formosa (GO), tomando-se discentes do $9^{\circ}$ ano do ensino fundamental do município de Formosa-GO. Alguns elementos relevantes podem ser ressaltados a partir da pesquisa. Um deles diz respeito ao fato de a maioria dos alunos considerar a disciplina de Ciências com grau de dificuldade mediano ("mais ou menos"). Quer dizer, independente do recurso(s) didático(s) adotado(s) para a realização de uma aula, necessário se faz esclarecer o porquê de se utilizar determinada metodologia, com objetivos e estratégias metodológicas adequadas, bem definidas, para abordar o conteúdo que se intenta. Dos dados apresentados, percebeu-se um grande desinteresse dos alunos pela disciplina, que pode estar relacionado a diversos fatores, dentre eles a abordagem metodológica e a dificuldade dos alunos em estabelecer conexão do que é estudado com a sua realidade. O fato de não perceberem aplicação prática do que estudam também pode ser um fator a ser considerado desmotivante para estudar ciências.

No que tange à visão acerca da disciplina de Ciências, os fatores que mais influenciam para a afinidade dos alunos com a disciplina são os próprios conteúdos e a maneira pela qual são apresentados aos discentes, como uso de vídeos e atividades experimentais. O que mais desinteressa os alunos quanto à disciplina de Ciências são: a realização de cópias de textos e tarefas sem a devida explicação do professor. Além disso, a necessidade de realizar cálculos em conteúdos físicos e químicos levam os discentes a não gostarem da disciplina. A dificuldade em efetuar operações básicas de cálculos também é um fator agravante e, dessa forma, a realização de trabalhos conjuntos, como projetos, envolvendo as disciplinas de Ciências e Matemática constitui uma saída. Todavia, não cabe mascarar uma prática que há tempos se propaga no cenário educacional brasileiro: a precária formação inicial dos docentes, que acaba por refletir numa precária formação dos jovens e no desgosto dos alunos pela disciplina.

\section{Referências Bibliográficas}

ACADEMIA BRASILEIRA DE CIÊNCIAS. O Ensino de ciências e a educação básica: propostas para superar a crise. Rio de Janeiro: Academia Brasileira de Ciências, 2008. 56p.

BARDIN, L. Análise de conteúdo. Lisboa (Portugal): Edições 70, 2002. 
Primeiro semestre 2014, volume 1, número 16.

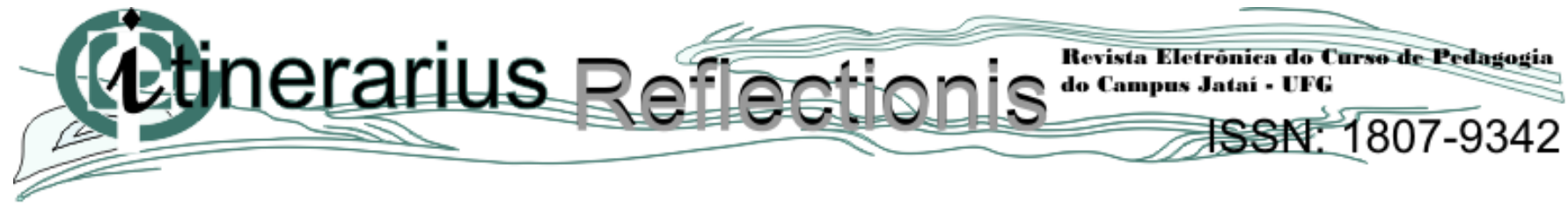

BOGDAN, R.C. e BIKLEN, S. K. Investigação qualitativa em educação: uma introdução à teoria e aos métodos. Porto: Porto Editora, 1994.

BRASIL. Secretaria de Educação Fundamental. Parâmetros Curriculares Nacionais: Ciências Naturais. Secretaria de Educação Fundamental. Brasília: MEC/SEF, 1998. 138 p.

CRUZ, V. A. G. Pesquisa em educação. São Paulo: Pearson Prentice Hall, 2009.

KRASILCHIK, M. Prática de ensino de biologia. 4. ed. São Paulo: USP, 2004.

LIMA, K. E. C.; VASCONCELOS, S. D. Análise da metodologia do ensino de Ciências nas escolas da rede municipal de Recife. Ensaio: avaliação, políticas públicas Educacionais, Rio de Janeiro, v.14, n.52, p. 397 412, 2006.

MALAFAIA, G.; RODRIGUES, A.S.L. Uma reflexão sobre o Ensino de Ciências no nível Fundamental da Educação. Ciência \& Ensino, Campinas, v. 2, n. 2, p. 1-9, 2008.

SANTOS, A. C. dos; CANEVER, C. F.; GIASSI, M. G.; FROTA, P. R de O. A importância do ensino de Ciências na percepção de alunos de escolas da rede pública municipal de Criciúma - SC. Revista Univap, v. 17, n. 30, p. 68-80, 2011.

TAPIA, J. A.; MONTERO, I. Orientação motivacional e estratégias motivadoras na aprendizagem escolar. In: COLL. C.; MARCHESI, A.; PALÁCIOS J. (orgs). Desenvolvimento psicológico e educação - 2: psicologia da educação escolar. Porto Alegre: Artes Médicas, 2003. p. 177-192. 
Primeiro semestre 2014, volume 1, número 16.

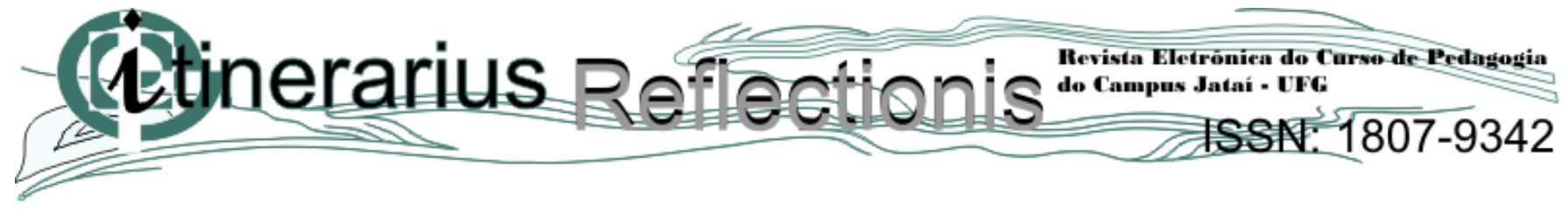

